\title{
Physical activity and semen quality among men attending an infertility clinic
}

\section{Citation}

Wise, Lauren A., Daniel W. Cramer, Mark D. Hornstein, Rachel K. Ashby, and Stacey A. Missmer. 2011. "Physical Activity and Semen Quality Among Men Attending an Infertility Clinic." Fertility and Sterility 95 (3) (March): 1025-1030. doi:10.1016/j.fertnstert.2010.11.006.

\section{Published Version}

doi:10.1016/j.fertnstert.2010.11.006

\section{Permanent link}

http://nrs.harvard.edu/urn-3:HUL.InstRepos:27332763

\section{Terms of Use}

This article was downloaded from Harvard University's DASH repository, and is made available under the terms and conditions applicable to Other Posted Material, as set forth at http:// nrs.harvard.edu/urn-3:HUL.InstRepos:dash.current.terms-of-use\#LAA

\section{Share Your Story}

The Harvard community has made this article openly available.

Please share how this access benefits you. Submit a story.

\section{Accessibility}




\title{
Physical activity and semen quality among men attending an infertility clinic
}

\author{
Lauren A. Wise, Sc.D. ${ }^{1}$, Daniel W. Cramer, M.D. ${ }^{2}$, Mark D. Hornstein, M.D. ${ }^{2}$, Rachel K. \\ Ashby, M.D. ${ }^{2}$, and Stacey A. Missmer, Sc.D.2,3,4 \\ ${ }^{1}$ Slone Epidemiology Center, Boston University, Boston, MA, USA \\ ${ }^{2}$ Department of Obstetrics, Gynecology, and Reproductive Biology, Brigham \& Women's Hospital \\ and Harvard Medical School, Boston, MA, USA \\ ${ }^{3}$ Channing Laboratory, Department of Medicine, Brigham \& Women's Hospital and Harvard \\ Medical School, Boston, MA, USA \\ ${ }^{4}$ Department of Epidemiology, Harvard School of Public Health, Boston, MA, USA
}

\begin{abstract}
OBJECTIVE-To examine the association between regular physical activity and semen quality.

DESIGN-Prospective cohort study.

SETTING-Couples attending one of three IVF clinics in the greater Boston area during 19932003. At study entry, male participants completed a questionnaire about their general health, medical history, and physical activity. Odds ratios (OR) and 95\% confidence intervals (CI) were derived using generalized estimating equations models, accounting for potential confounders and multiple samples per man.
\end{abstract}

PATIENTS-A total of 2,261 men contributing 4,565 fresh semen samples were enrolled before undergoing their first IVF cycle.

INTERVENTION-None.

MAIN OUTCOME MEASURES-Semen volume, sperm concentration, sperm motility, sperm morphology, and total motile sperm (TMS).

RESULTS-Overall, none of the semen parameters was materially associated with regular exercise. Compared with no regular exercise, bicycling $\geq 5$ hours per week was associated with low sperm concentration $(\mathrm{OR}=1.92,95 \% \mathrm{CI}=1.03-3.56)$ and low $\mathrm{TMS}(\mathrm{OR}=2.05,95 \% \mathrm{CI}=1.19$ 3.56). These associations did not vary appreciably by age, body mass index, or history of male factor infertility.

CONCLUSIONS-While the present study suggests no overall association between regular physical activity and semen quality, bicycling at levels of $\geq 5$ hours per week was associated with lower sperm concentration and TMS.

(C) 2010 American Society for Reproductive Medicine. Published by Elsevier Inc. All rights reserved

Reprint requests: Dr. Lauren A. Wise, Slone Epidemiology Center at Boston University, 1010 Commonwealth Avenue, Boston, MA, 02215; Telephone (617) 734-6006; Fax (617) 738-5119. lwise@bu.edu.

Publisher's Disclaimer: This is a PDF file of an unedited manuscript that has been accepted for publication. As a service to our customers we are providing this early version of the manuscript. The manuscript will undergo copyediting, typesetting, and review of the resulting proof before it is published in its final citable form. Please note that during the production process errors may be discovered which could affect the content, and all legal disclaimers that apply to the journal pertain. 


\section{Keywords}

physical activity; bicycling; sperm motility; sperm count; male infertility; IVF

\section{INTRODUCTION}

The American College of Sports Medicine and the American Heart Association recommend at least 30 minutes of moderate exercise on 5 days each week or at least 20 minutes of vigorous exercise on 3 days each week (1). While exercise has been associated with many health benefits, including reduced risks of obesity, diabetes, cardiovascular disease, and some cancers (2), the relation between exercise and male fertility has not been well-studied.

Male athletes, particularly long-distance runners, have been shown to have reduced testosterone levels (3-12). In addition, elevated scrotal temperature associated with certain types of exercise may cause atrophy of the testicular germinal epithelium and adversely affect spermatogenesis $(4,13,14)$. Bicycle riding has been linked to several genitourinary problems $(15,16)$, and two studies among competitive cyclists reported changes in semen parameters including abnormal sperm morphology (17) and reduced sperm motility during periods of racing (14).

We prospectively examined the association between regular exercise and semen quality among men attending an infertility clinic in Massachusetts during 1993-2003. The few studies that have evaluated this association have been small and confined to competitive athletes or have evaluated only a single type of exercise $(4,14,17)$. The present study, based on a larger general male population, addresses gaps in the literature on exercise and male fertility.

\section{MATERIALS AND METHODS}

We used data from the male partner of couples undergoing infertility treatment during 19932003 at three IVF clinics in the greater Boston area as part of a collaborative prospective study sponsored by the NICHD. The study's primary aim was to identify predictors of IVF outcomes, including regular exercise. Couples consented to a review of their medical records and completed a self-administered questionnaire before starting IVF treatment. Men were asked to provide at least one semen sample. Sixty-five percent of couples approached agreed to participate in the study. The study was approved by the Brigham and Women's Hospital Institutional Review Board, and patients gave written informed consent before enrolment.

The baseline questionnaire included questions about medical history, lifestyle, behavioral factors, and exercise questions phrased as follows: 1) Do you regularly exercise? 2) If so, as an adult, how many years have you engaged in regular exercise? 3) How many hours per week do you exercise? 4) How many months per year do you exercise? and 5) What is your most frequent type of exercise? Participants could list more than one type of exercise.

\section{Exercise}

Our primary exposure of interest was total metabolic equivalent (MET)-hours of physical activity per week, a measure of exercise intensity. Exercise intensities were defined according to the compendium of physical activities (18). To estimate total METs per week, we summed the METs from all activity types and computed the average METs per participant across all activities. We then multiplied the average METs by the total hours of activity reported per week. We also categorized men according to their average exercise 
intensity for all activities in which they were engaged, with $<4$ METs defined as "low," 4-6 METs "moderate," and $\geq 7$ METs "vigorous." The latter variable did not take into account exercise frequency. Finally, we grouped men according to frequency of their primary type of exercise $(\leq 2,3-4, \geq 5$ hours/week).

\section{Semen parameters}

Men were requested to observe a 2- to 5-day abstinence period before providing a semen sample. At each study visit, men collected semen samples by masturbation at the clinic and samples were analyzed within 20 minutes of collection on average (range: 15-60 minutes). Sperm concentration assessments were evaluated by hemacytometer (Improved Neubauer; Hauser Scientific Inc., Horsham, PA). Ejaculate volumes were measured using a standard $10 \mathrm{ml}$ laboratory pipette. Percent motile sperm was counted in a MicroCell chamber (Conception Technologies, San Diego, CA) and refers to percentage of sperm with any flagellar movement, whether twitching or progressive. Motility was analyzed using the World Health Organization (WHO) 1999 definition (19). Seminal smears were prepared at each clinical center where they were Papanicalou stained, analyzed, and stored, and where a single technician assessed sperm morphology using either the WHO (19) or Kruger method $(20,21)$, depending on the center. Total motile sperm (TMS, units: $\left.10^{6}\right)$ was computed by multiplying sperm concentration by semen volume by percent motile sperm (22).

\section{Exclusions}

A total of 2,481 men, contributing 5,737 semen samples (IVF cycles), were enrolled. We excluded 848 samples with missing or implausible values on all semen parameters, 119 frozen samples, 96 non-ejaculate samples, and 109 samples from men with missing exercise data. After these exclusions, 2,261 men contributing 4,565 fresh semen samples remained. Excluded participants were similar to those included with respect to mean age (37.6 vs. 36.9 years), exercise intensity (16.5 vs. 16.2 METs), college education (34.5 vs. 35.2\%), current smoking (11.9 vs. $10.1 \%$ ), and multivitamin use (44.2 vs. $45.6 \%)$, but were more likely to have a history of male factor infertility ( 40.9 vs. $26.4 \%$ ). Approximately $17 \%$ and $26 \%$ of couples discontinued treatment after the first and second IVF cycle, respectively, with discontinuation being more prevalent among older and parous women (23).

\section{Data analysis}

Exercise categories were based on their frequency distribution in the sample. Primary outcomes were sperm concentration, semen volume, percent motility, TMS, and percent normal morphology. We examined the odds of being classified below WHO thresholds (19) based on sperm concentration $(<20 \mathrm{million} / \mathrm{ml})$, volume $(<2 \mathrm{ml})$, and motility $(<50 \%$ motile sperm). For TMS, we used a cutpoint of below the $25^{\text {th }}$ percentile $\left(<23 \times 10^{6}\right.$ motile sperm). While WHO has no comparable cutoff for morphology, we defined "abnormal morphology" as normal forms $<30 \%$ by standard criteria (19) and $<4 \%$ by Kruger criteria (20).

We used generalized estimating equations to calculate odds ratios (ORs) and 95\% confidence intervals (CIs) for the relation between exercise and semen parameters, accounting for multiple samples contributed per man. The mean (and median) number of samples provided per man was two (range: 1-10), with 1,024 (45\%) providing one semen sample, 613 (27\%) two samples, 355 (16\%) three samples, and $269(12 \%)$ four or more samples. Men reporting no regular exercise were the reference group in all analyses.

We controlled for known or suspected confounders, including age (years), body mass index $\left(\mathrm{BMI}=\mathrm{kg} / \mathrm{m}^{2}\right)$, multivitamin use (yes vs. no), history of urogenital anomalies (yes vs. no), history of prostate or sexually transmitted infections (yes vs. no), history of male factor infertility (yes vs. no), current alcohol consumption (g/week), current caffeine consumption 
(mg/week), smoking (current, former, never), type of underwear most commonly worn (boxers, briefs, boxers $\&$ briefs), hypertension (yes vs. no), education ( $\leq$ high school, some college or vocational, college, graduate school), and race/ethnicity (white vs. non-white). Missing data were modeled using indicator variables. We also controlled for study site and study wave (1993-1998; 1999-2003) to account for any differences in referral patterns or time period.

P-values for interaction were obtained from a likelihood ratio test comparing models with and without cross-product terms of each semen characteristic with age and BMI. All $P$ values were based on two-tailed tests, with statistical significance indicated by $P=0.05$ (95\% confidence interval excluding one). SAS statistical software (version 9.1) was used for all analyses (24).

\section{RESULTS}

The median age of participants was 36 years (interquartile range: $33-40$ years), median BMI was $22.7 \mathrm{~kg} / \mathrm{m}^{2}$ (interquartile range: $20.8-25.7 \mathrm{~kg} / \mathrm{m}^{2}$ ), and $91 \%$ were white (data not shown). About $26 \%$ reported fathering a previous pregnancy, $26 \%$ reported a history of male factor infertility, and $13 \%$ had received IVF or GIFT previously. Of the men who exercised regularly, the median number of hours exercised per week was 4.0 (interquartile range: 2.5 6.0 hours), the median METs of exercise averaged across all exercise types was 7.0 (interquartile range: 4.8-8.0), and the median total MET-hours/ week was 24.0 (interquartile range: $14.0-36.0)$.

Baseline characteristics of the sample according to MET-hours/week of exercise are shown in Table 1. Men reporting regular exercise were more likely to be educated, lean, and use multivitamins, and were less likely to smoke, consume caffeine, or have hypertension. Positive associations were found between low TMS and male age $(\mathrm{OR}=1.04$ per year, $\mathrm{p}<0.001)$, BMI $\left(\mathrm{OR}=1.03\right.$ per $\left.\mathrm{kg} / \mathrm{m}^{2}, \mathrm{p}<0.001\right)$, history of urogenital anomaly $(\mathrm{OR}=1.48$, $\mathrm{p}=0.02$ ), education ( $\leq$ high school vs. graduate school; $\mathrm{OR}=1.54, \mathrm{p}=0.03$ ), and history male factor infertility $(\mathrm{OR}=8.93, \mathrm{p}<0.001)$. Abnormal sperm morphology was associated with male factor infertility only $(\mathrm{OR}=2.77, \mathrm{p}<0.001)$.

None of the semen parameters was materially associated with regular exercise, MET-hours/ week of activity, or average exercise intensity (Table 2). When we examined the relation between type of exercise and semen parameters (Table 3), bicycling was associated with low sperm concentration and low TMS. Compared with no regular exercise, ORs associated with bicycling $\leq 2,3-4$, and $\geq 5$ hours per week were 1.31 (95\% CI=0.57-3.02), 2.09 (95\% $\mathrm{CI}=0.90-4.83)$, and $1.92(95 \% \mathrm{CI}=1.03-3.56)$, respectively, for low sperm concentration $(P$ trend $=0.01)$ and 0.77 (95\% CI=0.34-1.76), 1.44 (95\% CI=0.69-3.01), and 2.05 (95\% $\mathrm{CI}=1.19-3.56)$, respectively, for low TMS $(P$ trend $=0.02)$.

Associations of bicycling with low sperm concentration and low TMS persisted across categories of BMI and age. ORs for low sperm concentration comparing $\geq 5$ hours/week of bicycling with no regular exercise were $2.33(95 \% \mathrm{CI}=1.04-5.23 ; P$-trend=0.01) among men with $\mathrm{BMI}<25 ; 2.06(95 \% \mathrm{CI}=0.64-6.60 ; P$-trend $=0.24)$ among men with $\mathrm{BMI} \geq 25(P$ interaction by $\mathrm{BMI}=0.92) ; 2.08(95 \% \mathrm{CI}=0.86-5.02 ; P$-trend=0.11) among men aged $<40$; and $1.49(95 \% \mathrm{CI}=0.52-4.30 ; P$-trend $=0.10)$ among men aged $\geq 40(P$-interaction by age $=0.21$ ). ORs for low TMS comparing $\geq 5$ hours/week of bicycling with no regular exercise were 2.15 (95\% $\mathrm{CI}=1.16-3.96 ; P$-trend $=0.05)$ among men with $\mathrm{BMI}<25 ; 2.57$ $(95 \% \mathrm{CI}=0.80-8.23 ; P$-trend $=0.12)$ among men with $\mathrm{BMI} \geq 25$ ( $P$-interaction by BMI $=0.77) ; 1.80(95 \% \mathrm{CI}=0.80-4.10 ; P$-trend $=0.44)$ among men aged $<40$; and $2.16(95 \%$ $\mathrm{CI}=0.87-5.32 ; P$ trend $=0.01)$ among men aged $\geq 40(P$-interaction by age $=0.31)$. In addition, 
associations of bicycling with low sperm concentration and TMS were apparent when we confined the analysis to: 1) men without a history of male factor infertility, or 2) the first semen sample provided by each man $(\mathrm{N}=2,261)$, albeit the ORs were weaker and less precise (data not shown).

\section{DISCUSSION}

In the present study, there was little evidence for an overall effect of regular exercise on sperm concentration, volume, sperm motility, TMS, or morphology. However, in the subgroup of men who reported bicycling as their primary form of exercise, bicycling at levels of $\geq 5$ hours per week was associated with low sperm concentration and TMS. These findings, from a study of moderate exercisers, generally agree with previous studies that have shown deleterious effects of bicycling on semen parameters among competitive cyclists $(14,17)$.

The few studies that have evaluated the relation between exercise and semen quality have been confined to one or two types of activity, or have examined endurance or high-intensity athletic training only, making it difficult to compare results. Our null results for jogging and running do not support the few studies that have shown significant alterations in sperm count (5), concentration $(4,5,11)$, motility $(4,5,11)$, and morphology $(4,11)$ among endurance-trained runners (4), high-mileage runners (5), and high-intensity long-term treadmill runners (11). However, the runners in our study had more moderate levels of exercise, potentially limiting statistical power to detect a true effect. A previous study found that "high-mileage" runners (mean: $108 \mathrm{~km} / \mathrm{wk}$ ) experienced significant alterations in semen quality relative to sedentary men (5), but not runners of "moderate mileage" (mean: $54 \mathrm{~km} /$ wk), similar to what another study found among three groups of athletes differing in exercise intensity and frequency (12). Therefore, another explanation is that running at the levels observed in our study may not influence semen quality.

Study limitations include self-reported exercise data and the evaluation of activity for current exercisers only. For example, lifetime exercisers who eliminated their activity prior to completing the baseline questionnaire would have been misclassified as non-exercisers. Furthermore, in the analyses of exercise subtypes, there was no information on the actual intensity of the activity. For instance, two men who reported bicycling $\geq 5$ hours/week could have had vastly different intensities of bicycling (e.g., leisurely cycling for transportation versus competitive cycling). Such errors in classification would generally dilute our effect estimates.

Although exclusions at baseline were similar according to several risk factors for infertility, men reporting a history of male factor infertility were more likely to be excluded. Couples whose IVF treatment included donor sperm were ineligible for enrollment, precluding analysis of their data. While such exclusions may have reduced variability in semen quality, it is unlikely that these exclusions were a significant source of bias because our findings persisted among men with and without a history of male factor infertility. Finally, our results did not differ markedly by the number of semen samples provided over follow-up,

suggesting that results did not depend on success with IVF treatment.

Study strengths include the large sample size and the collection of multiple cycles of data over a 10 -year period. Because men reported their exercise and covariate data before the provision of a semen sample, reporting errors are not likely to depend on the measurement of semen quality. Thus, our effect estimates comparing extreme categories of exercise are probably conservative. We controlled for a wide range of potential confounders such as age, 
BMI, smoking, and history of infections. Given all outcome data were abstracted from medical records, we had nearly complete information on the study endpoints of interest.

A link between reduced sperm concentration and bicycling - the one class of exercise to show an effect-has some biologic plausibility. Bicycling has been linked to genitourinary problems $(15,16)$, including nerve entrapment syndromes (50-91\% of cyclists), erectile dysfunction (13-24\%), and other less common symptoms (priapism, penile thrombosis, hematuria, torsion of spermatic cord, perineal nodular induration, and prostatitis) (16). Two studies among long-distance competitive cyclists reported changes in semen parameters including a lower percentage of sperm with normal morphology (17), a higher proportion of morphologically abnormal tapered forms (17), and reduced sperm motility (14). Moreover, small changes in total and free testosterone have been observed in male athletes (3-12), potentially affecting spermatogenesis. It remains unclear as to whether the changes associated with bicycling are due to mechanical trauma (i.e., caused by compression of scrotum on bicycle saddle), to a prolonged increase in core scrotal temperature (i.e., related to exercise itself or wearing of constrictive clothing), or some other factor (16). A report among moderate bicyclers showed no correlation between cycling duration and scrotal temperature (25).

Because men who attend infertility clinics differ from the general population of reproductive-aged men, caution should be used when interpreting our findings. If those attending infertility clinics differ with respect to exercise levels and semen quality, our results may not extend to a larger population of men. However, it is unlikely that the exercise levels of men in our study differed materially from those of the general population. Moreover, because associations were uniform across levels of age and BMI, our findings, if real, may extend to other groups of men with similar characteristics.

In summary, in this study of moderate exercisers, no association was observed between regular exercise and semen parameters overall, but bicycling at levels of $\geq 5$ hours per week was associated with reduced sperm concentration and TMS. Our findings warrant confirmation in larger studies of moderate bicyclers and men from the general population.

\section{Acknowledgments}

This work was supported by grant HD32153 from the Eunice Kennedy Shriver National Institute of Child Health and Human Development. We wish to acknowledge the technical assistance of Allison F. Vitonis, M.Sc., and the ongoing contributions of study participants.

\section{REFERENCES}

1. Haskell WL, Lee IM, Pate RR, Powell KE, Blair SN, Franklin BA, et al. Physical activity and public health: updated recommendation for adults from the American College of Sports Medicine and the American Heart Association. Circulation 2007;116:1081-1093. [PubMed: 17671237]

2. Blair SN, Morris JN. Healthy Hearts and the Universal Benefits of Being Physically Active Physical Activity and Health. Annals of epidemiology 2009;19:253-256. [PubMed: 19344864]

3. Arce JC, De Souza MJ. Exercise and male factor infertility. Sports Med 1993;15:146-169. [PubMed: 8451548]

4. Arce JC, De Souza MJ, Pescatello LS, Luciano AA. Subclinical alterations in hormone and semen profile in athletes. Fertil Steril 1993;59:398-404. [PubMed: 8425638]

5. De Souza MJ, Arce JC, Pescatello LS, Scherzer HS, Luciano AA. Gonadal hormones and semen quality in male runners. A volume threshold effect of endurance training. Int J Sports Med 1994;15:383-391. [PubMed: 8002116]

6. Hackney AC. Exercise as a stressor to the human neuroendocrine system. Medicina (Kaunas) 2006;42:788-797. [PubMed: 17090977] 
7. Hackney AC. Effects of endurance exercise on the reproductive system of men: the "exercisehypogonadal male condition". J Endocrinol Invest 2008;31:932-938. [PubMed: 19092301]

8. Daly W, Seegers CA, Rubin DA, Dobridge JD, Hackney AC. Relationship between stress hormones and testosterone with prolonged endurance exercise. Eur J Appl Physiol 2005;93:375-380. [PubMed: 15618989]

9. Hill EE, Zack E, Battaglini C, Viru M, Viru A, Hackney AC. Exercise and circulating cortisol levels: the intensity threshold effect. J Endocrinol Invest 2008;31:587-591. [PubMed: 18787373]

10. Viru AM, Hackney AC, Valja E, Karelson K, Janson T, Viru M. Influence of prolonged continuous exercise on hormone responses to subsequent exercise in humans. Eur J Appl Physiol 2001;85:578-585. [PubMed: 11718288]

11. Safarinejad MR, Azma K, Kolahi AA. The effects of intensive, long-term treadmill running on reproductive hormones, hypothalamus-pituitary-testis axis, and semen quality: a randomized controlled study. J Endocrinol 2009;200:259-271. [PubMed: 19066291]

12. Vaamonde D, Da Silva-Grigoletto ME, García-Manso JM, Vaamonde-Lemos R, Swanson RJ, Oehninger SC. Response of semen parameters to three training modalities. Fertility and Sterility 2009;92:1941-1946. [PubMed: 19013565]

13. Munkelwitz R, Gilbert BR. Are boxer shorts really better? A critical analysis of the role of underwear type in male subfertility. J Urol 1998;160:1329-1333. [PubMed: 9751347]

14. Lucia A, Chicharro JL, Perez M, Serratosa L, Bandres F, Legido JC. Reproductive function in male endurance athletes: sperm analysis and hormonal profile. J Appl Physiol 1996;81:26272636. [PubMed: 9018515]

15. Asplund C, Barkdull T, Weiss BD. Genitourinary problems in bicyclists. Curr Sports Med Rep 2007;6:333-339. [PubMed: 17883970]

16. Leibovitch I, Mor Y. The vicious cycling: bicycling related urogenital disorders. Eur Urol 2005;47:277-286. discussion 86-7. [PubMed: 15716187]

17. Gebreegziabher Y, Marcos E, McKinon W, Rogers G. Sperm characteristics of endurance trained cyclists. Int J Sports Med 2004;25:247-251. [PubMed: 15162242]

18. Ainsworth BE, Haskell WL, Whitt MC, Irwin ML, Swartz AM, Strath SJ, et al. Compendium of physical activities: an update of activity codes and MET intensities. Med Sci Sports Exerc 2000;32:S498-S504. [PubMed: 10993420]

19. World Health Organization. 4th ed.Cambridge UK/New York: Cambridge University Press; 1999. WHO laboratory manual for the examination of human semen and semen-cervical mucus interactions.

20. Kruger TF, Menkveld R, Stander FS, Lombard CJ, Van der Merwe JP, van Zyl JA, et al. Sperm morphologic features as a prognostic factor in in vitro fertilization. Fertil Steril 1986:1118-1123. [PubMed: 2946611]

21. Kruger TF, Coetzee K. The role of sperm morphology in assisted reproduction. Hum Reprod Update 1999;5:172-178. [PubMed: 10336021]

22. Brazil C, Swan SH, Drobnis EZ, Liu F, Wang C, Redmon JB, et al. Standardized Methods for Semen Evaluation in a Multicenter Research Study. J Androl 2004;25:635-644. [PubMed: 15223853]

23. Pearson KR, Hauser R, Cramer DW, Missmer SA. Point of failure as a predictor of in vitro fertilization treatment discontinuation. Fertility and Sterility 2009;91:1483-1485. [PubMed: 18829010]

24. SAS Institute Inc.. SAS/STAT User's Guide. Version 9.1. Cary, NC: SAS Institute; 2004.

25. Jung A, Strauss P, Lindner HJ, Schuppe HC. Influence of moderate cycling on scrotal temperature. Int J Androl. 2007 


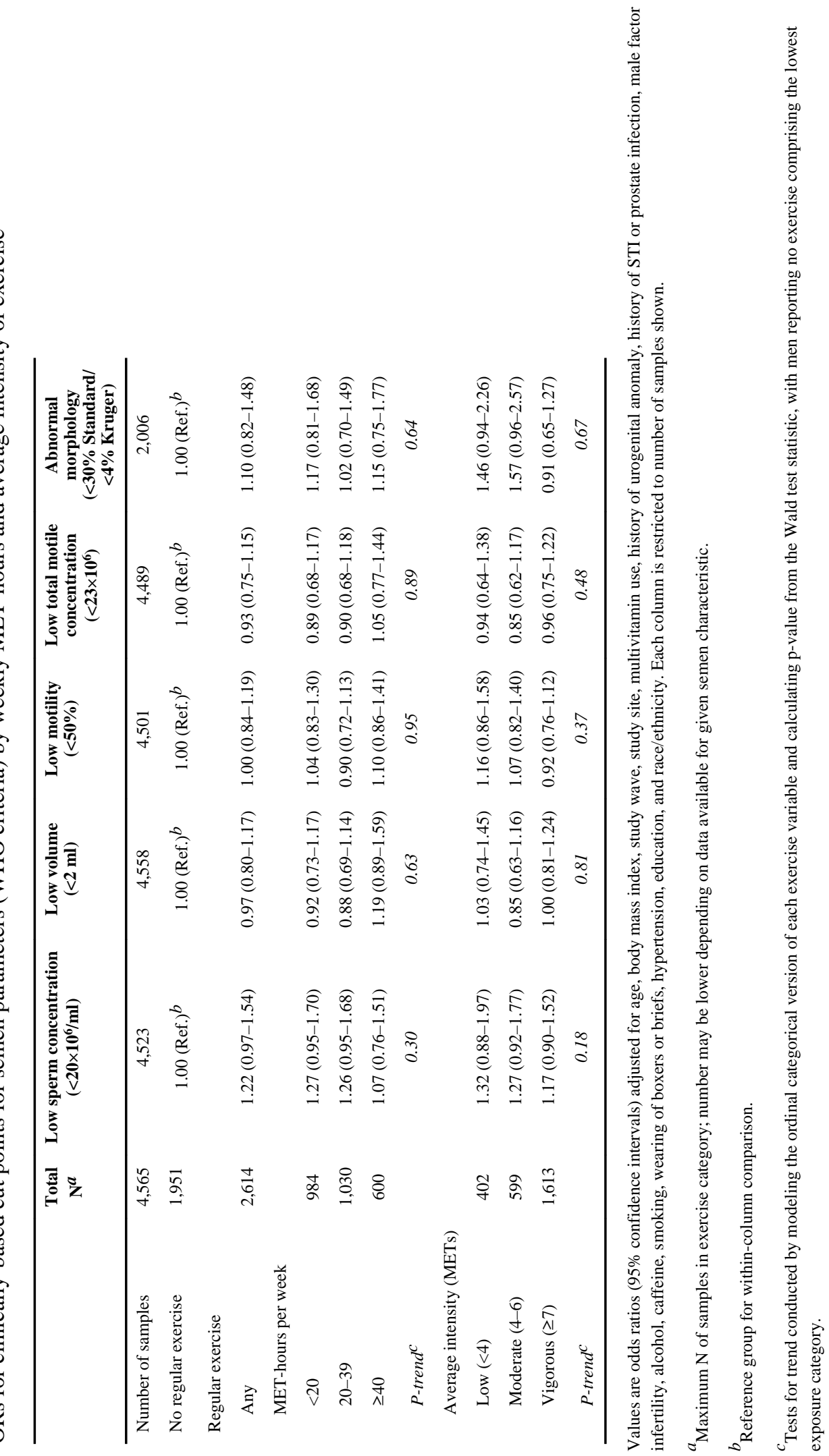




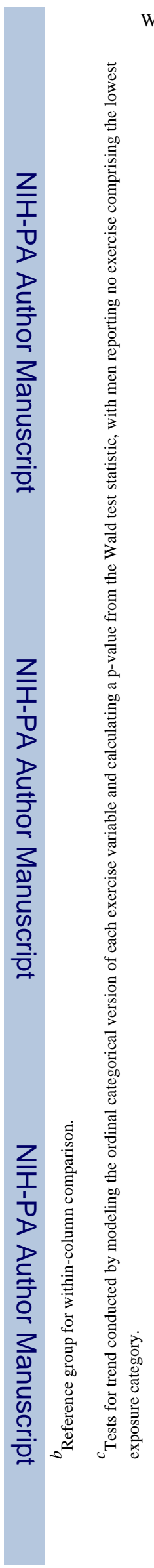

Wise et al.

Page 11

Fertil Steril. Author manuscript; available in PMC 2012 March 1. 